\title{
Risk factors for anxiety and depression in patients diagnosed with glaucoma at the Philippine General Hospital
}

\author{
Christine S. Siguan-Bell, Nilo Vincent D. G. Florcruz \\ Department of Ophthalmology and Visual Sciences, UP-Philippine General \\ Hospital, Manila, Philippines
}

\begin{abstract}
Objective: The main objective of this study is to identify the risk factors associated with anxiety and depression among Filipino patients with glaucoma at a tertiary hospital in Manila. The study also aims to determine the sociodemographic profile of patients diagnosed with glaucoma based on age, sex, and social history. Additionally, the study seeks to determine the prevalence of anxiety and depression among Filipino glaucoma patients.
\end{abstract}

Methods: This is a single-center, cross-sectional study. The levels of anxiety and depression in 82 glaucoma patients, seen in a tertiary hospital in Manila, were evaluated using the Filipino version of the Hospital Anxiety and Depression Scale (HADS-P) questionnaire, which consists of two subscales, representing HADS-anxiety (HADS-A) and HADS-depression (HADS-D). The sociodemographic profile of the glaucoma patients was identified using percentages and frequency distribution. The prevalence of anxiety and depression among the participants was determined using percentages. To identify the risk factors for anxiety and depression, Pearson correlation and linear regression analysis were performed with the HADS-A and HADS-D subscores as dependent variables and demographic and clinical features as independent variables.

Results: After analyzing the data available, it was noted that HADS-A score $\geq 11$ was present in $15 \%$ of cases, indicating anxiety among the glaucoma patients. Borderline cases of anxiety were observed in 20\% (HADS-A score of 8-10), and 65\% were normal, with HADS-A scores of $\leq 7$. Clinically diagnosed (HADS-D score of $\geq 11$ ) cases of depression were $1 \%$, borderline cases (HADS-D 8-10) were $12 \%$, and patients with normal HADS-D score were $87 \%$. The linear regression analysis revealed the following results: a significant relationship between the HADS- $A$ subscore and age $(B=-0.07, p=0.0129)$; a significant relationship between the logarithm of minimum angular resolution (logMAR) best corrected visual acuity (BCVA) of the worse eye and HADS-A subscore ( $B=0.424, p=0.086)$; and the mean deviation of the worse eye and HADS-A subscore $(B=0.078, p=0.025)$. The linear regression analysis revealed the following statistically significant relationships: HADS-D subscores and age $(B=-0.06, p=0.0125)$; logMAR $B C V A$ of the worse eye and HADS-D subscore $(B=0.541, p=0.006)$; mean deviation of

Correspondence: Dr. Christine Siguan Bell, Department of Ophthalmology and Visual Sciences, UP-Philippine General Hospital, Manila, Philippines.

E-mail: christinesiguan@yahoo.com 
the worse eye and HADS-D subscore $(B=0.070, p=0.016)$; and mean deviation of the better eye and HADS-D subscore $(B=0.097, p=0.032)$.

Conclusion: This study shows that the prevalence of anxiety is higher than that of depression in patients with glaucoma. It can also be concluded that younger age is a risk factor for both anxiety and depression. The patient's visual acuity in the worse eye and visual field severity are also risk factors for both anxiety and depression. It is therefore essential for physicians to be aware of the risk factors for anxiety and depression in patients with glaucoma and to provide glaucoma patients with appropriate psychological care, in addition to ophthalmological care, to prevent the development of these psychological conditions.

Keywords: anxiety, depression, glaucoma, Hospital Anxiety and Depression Scale, psychological disturbance

\section{Introduction}

Glaucoma is one of the most common chronic eye diseases where blindness is a potential outcome. Due to its asymptomatic, chronic nature and potential to result in blindness, it can often impose a psychological burden on patients. ${ }^{1,2}$ Anxiety and depression are two common forms of psychological disturbance, and previous studies have shown that patients with glaucoma have a greater likelihood of having these conditions., ${ }^{3,4}$ In a study by Mabuchi et al. comparing patients with primary open angle-glaucoma (POAG) with sex- and age-matched reference subjects, using the Hospital Anxiety and Depression Scale (HADS), it was shown that the prevalence of anxiety or depression was higher in POAG patients than in the reference subjects, which supports the view that glaucoma is related to anxiety and depression and detrimentally affects the quality of life of glaucoma patients. ${ }^{3,5}$ Anxiety is characterized by excessive, uncontrollable, and often irrational worry, that is, apprehensive expectation about events or activities. On the other hand, depression is a state of low mood and aversion to activity that can affect thoughts, behavior, feelings, and sense of well-being, as defined by the Diagnostic and Statistical Manual of Mental Disorders V. ${ }^{6}$

Younger age, female gender, and having a moderate or heavy economic burden are risk factors for anxiety, while being older and having increased severity and duration of glaucoma are risk factors for depression, as noted by the studies of $\operatorname{Tastan}^{7}$ and Mabuchi et al. ${ }^{8}$ Glaucoma also negatively affects psychosocial functioning. Chan and associates noted that early-stage glaucoma with mild visual field (VF) loss adversely affects anxiety, self-image, and confidence in health care. As visual acuity worsens in advanced glaucoma, anxiety further increases and self-image deteriorates. ${ }^{5}$ Providing glaucoma patients with appropriate psychological care is therefore essential to improving their quality of life and drug compliance. In order to detect, prevent, and treat the emotional problems that 
can develop in glaucoma patients, it is important to understand the risk factors for these psychological disturbances.

There were several psychometric tools used in the studies mentioned, namely, HADS questionnaire, 25-item National Eye Institute Visual Functioning Questionnaire, and the 36-item Glaucoma Quality of Life questionnaire. The HADS questionnaire was used in the studies of Mabuchi et al., ${ }^{8}$ Zhou et al., ${ }^{9}$ and Kong et al. ${ }^{10}$ It was developed by Zigmond and Snaith ${ }^{11}$ to identify and quantify the two most common forms of psychological disturbance in medically ill patients - anxiety and depression. The original HADS was translated into Chinese Mandarin and Japanese and has been validated in many studies. ${ }^{11,12}$ The HADS has also been translated into Filipino (HADS-P) and has been used in three local studies in a tertiary hospital in Manila. In 2004, it was used to screen for anxiety and depression in Filipino epileptics, ${ }^{13}$ and in 2012 and 2013 it was used to ascertain the prevalence and causes of anxiety and depression among Filipino chronic obstructive pulmonary disease patients. ${ }^{14,15}$ The third national survey on blindness, conducted in the Philippines in 2002, ranked glaucoma as the third most common cause of bilateral blindness in the country and the fifth most common cause of low vision. The survey projected that a total of 71,821 Filipinos have glaucoma, 18,620 of whom are bilaterally blind. ${ }^{16}$ However, no local studies have been conducted to determine the presence of anxiety and depression among Filipino glaucoma patients.

The main objective of this study is to identify the risk factors associated with anxiety and depression among Filipino patients with glaucoma seen in a tertiary hospital in Manila. It also aims to determine the sociodemographic profile of patients diagnosed with glaucoma, based on age, sex, and social history. In addition, the study seeks to determine the prevalence of anxiety and depression among Filipino glaucoma patients.

\section{Methodology}

This is a single-center, cross-sectional study. Patients with clinically diagnosed glaucoma, including those with POAG, exfoliation glaucoma, primary angleclosure glaucoma (PACG), and secondary glaucoma (SG), seen from June 2015 to September 2015 at the glaucoma clinic of the Department of Ophthalmology and Visual Sciences, Philippine General Hospital, were recruited for the study. The inclusion criteria were: Filipino-speaking adult patients (18 years and above) with clinically diagnosed glaucoma, based on typical glaucomatous cupping of the optic disc, with compatible VF defects detected by automated static perimeter (Humphrey VF analyzer 30-2, 24-2, and/or Octopus G1 program) in one or both eyes. Only reliable VFs, determined by false-positive results, false-negative results, or fixation losses not exceeding $33 \%$, were used. The exclusion criteria were: patients with any other coexisting ocular condition that could impair 
visual function and cause VF defects, for example, a visually significant cataract, retinal or neural pathology; patients with diagnosed psychiatric illnesses prior to diagnosis of glaucoma; patients who underwent incisional ocular surgery or laser treatment within the previous month; patients currently using antipsychotic or other medicines that might cause psychological disturbance; and patients demonstrating disability in a VF test due to cognitive impairment. Those who had recently experienced grief due to severe illness, death, or any other cause in the immediate family within the previous six months were also excluded. The formula used to compute the sample size was the one appropriate for a descriptive questionnaire-type cross-sectional study:

$$
\text { ss }=\frac{Z^{2} \times(p) \times(1-p)}{c^{2}},
$$

where ss is the sample size, $Z$ is the $Z$ value ( $90 \%$ confidence level), $p$ is the percentage picking a choice, expressed as a decimal ( 0.5 used for sample size needed), and $c$ is the confidence interval, expressed as a decimal $(0.1= \pm 10)$.

A sample size of 82 patients will result in a $90 \%$ confidence level with \pm 10 confidence interval, with $9.05 \%$ margin of error. Prior to enrollment, each participant was given a patient's information sheet explaining the study. Informed consent was also obtained.

Patients underwent a standard ophthalmologic examination (measurement of the uncorrected and corrected Snellen visual acuity, refraction, Goldmann applanation tonometry, a slit lamp biomicroscopic examination, gonioscopic examination, and optic nerve evaluation). Newly diagnosed glaucoma patients were subjected to a VF analysis with automated perimetry (Humphrey Field Analyser, Carl Zeiss Meditec AG, jena, Germany) using a 30-2 (HFA 30-2) or a 24-2 (HFA 24-2) threshold program, or the SITA standard strategy of the Octopus G1 program. The preexisting follow-up glaucoma patients recruited to the study used their old VF results and the mean deviation (MD) in the last HFA 30-2 or HFA 24-2 or Octopus G1 program taken within six months of enrolment in this study was used to evaluate VF loss. Once the patients were referred to the study, another examination was conducted to complete the data collection form. Sociodemographic characteristics such as age, sex, social history (educational background, marital status, living companions), medical history (previous medical history and family medical history), and ocular history (duration of glaucoma, history of glaucoma medication use, history of glaucoma laser procedure, and history of glaucoma surgery) were obtained.

The HADS questionnaire, developed by Zigmond and Snaith, was used to pinpoint anxiety and depression. In patients who are unwell, these are the two most common forms of psychological disturbances. The HADS focuses solely on 
psychological symptoms, while omitting physical symptoms, which could be attributed to the physical illness. It is a 14-item, self-assessment questionnaire, comprising seven items each for the anxiety subscale and depression subscale. The minimum total score of each of the seven-item subscales is 0 and the maximum is 21 . Higher scores indicate a higher level of depression and anxiety.

The HADS has been translated into several languages. The Filipino version (HADS-P) has been validated and is used in this study. The participants were requested to answer the questionnaire (see Appendix $A$ ) by themselves. The questionnaire was explained to them and assistance was provided where needed. In cases where participants were unable to read due to poor eyesight, their companion was asked to read the questionnaire to the patients and their answers were then recorded. The HADS-P was tested for validity and reliability, with a recommendation of 11 as the optimal cut-off score when screening for depression and anxiety in Filipino patients. A clinical diagnosis of anxiety or depression is likely if either of the two subclasses produces a total score of 11 or more. A score of 8 to 10 is considered borderline and a score of 7 or less is considered normal. ${ }^{17}$

Descriptive analysis was compiled for sociodemographic data and for the psychological profile. Mean \pm standard deviation with a minimum and maximum range of values was used for continuous data and frequency, with a percentage distribution for categorical data. To determine the prevalence of anxiety and depression among the participants, the frequency and percentages of both were calculated. To identify the associating factors for psychological disturbances (anxiety and depression) in patients with glaucoma, a Pearson correlation and linear regression analysis were used with the HADS-A and HADS-D subscores as dependent variables, and demographic and clinical features as independent variables. For statistical analysis, visual acuity was converted into a logarithm of minimum angular resolution (logMAR). For eyes that could not be examined by automated visual field (AVF) perimetry using HFA 30-2 or SITA G program because of poor visual function, the vision level of these eyes was assigned an MD value of $30.0 \mathrm{~dB}$. Eyes categorized as "no light perception," were assigned an MD value of $40.0 \mathrm{~dB}$. A p value $<0.10$ was considered to be statistically significant.

The study was approved by the research ethics board of the hospital and adhered to the tenets of the Declaration of Helsinki.

\section{Results}

Eighty-two glaucoma patients were interviewed for this study. Fifty percent of the participants were diagnosed with PACG, $32 \%$ with POAG, and $18 \%$ with SG. The sociodemographic profiles of the participants are shown in Table 1. The mean age of the participants was 61.6 years \pm 13.3 standard deviation, with an age range of 19 to 90 years. A total of 26 males and 56 females participated in the study. 
Risk factors for anxiety and depression in glaucoma patients

Table 1. Sociodemographic and clinical characteristics of participants

\begin{tabular}{|c|c|c|c|c|c|}
\hline Category & $\mathbf{N}(\mathbf{8 2})$ & $\begin{array}{l}\text { Percentage } \\
(100)\end{array}$ & Mean & $\begin{array}{l}\text { Standard } \\
\text { deviation }\end{array}$ & Range \\
\hline Age, years & & & 61.6 & 13.9 & $19-90$ \\
\hline $18-39$ & 6 & 7 & & & \\
\hline $40-60$ & 27 & 33 & & & \\
\hline$>60$ & 49 & 60 & & & \\
\hline \multicolumn{6}{|l|}{ Gender } \\
\hline Male & 26 & 32 & & & \\
\hline Female & 56 & 68 & & & \\
\hline \multicolumn{6}{|l|}{ Education } \\
\hline No formal education & 2 & 2 & & & \\
\hline Elementary & 27 & 33 & & & \\
\hline High school & 34 & 42 & & & \\
\hline College and above & 19 & 23 & & & \\
\hline \multicolumn{6}{|l|}{ Living status } \\
\hline Alone & 1 & 1 & & & \\
\hline Living with a partner & 7 & 9 & & & \\
\hline Living with family & 74 & 90 & & & \\
\hline \multicolumn{6}{|l|}{ Marital status } \\
\hline Married & 71 & 87 & & & \\
\hline Unmarried & 11 & 13 & & & \\
\hline Duration of glaucoma (years) & & & 5.82 & 5.83 & $0.08-29$ \\
\hline \multicolumn{6}{|l|}{ Type of glaucoma } \\
\hline POAG & 26 & 32 & & & \\
\hline PACG & 41 & 50 & & & \\
\hline SG & 15 & 18 & & & \\
\hline Number of medications & & & 2 & 1.03 & $0-5$ bottles \\
\hline
\end{tabular}




\begin{tabular}{|c|c|c|c|c|c|}
\hline Category & $N(82)$ & $\begin{array}{l}\text { Percentage } \\
(100)\end{array}$ & Mean & $\begin{array}{l}\text { Standard } \\
\text { deviation }\end{array}$ & Range \\
\hline \multicolumn{6}{|l|}{ Laser treatment } \\
\hline No & 46 & 56 & & & \\
\hline Yes & 36 & 44 & & & \\
\hline \multicolumn{6}{|l|}{ Surgical treatment } \\
\hline No & 19 & 23 & & & \\
\hline Yes & 63 & 77 & & & \\
\hline \multicolumn{6}{|l|}{ LogMAR BCVA } \\
\hline Better eye & & & 0.12 & 0.16 & $0-0.88$ \\
\hline Worse eye & & & 1.54 & 1.61 & $0-4$ \\
\hline \multicolumn{6}{|l|}{$\mathrm{IOP}, \mathrm{mmHg}$} \\
\hline Eye with lower IOP & & & 12 & 4.44 & 4-24 mmHg \\
\hline Eye with higher IOP & & & 22 & 13.99 & $7-80 \mathrm{mmHg}$ \\
\hline \multicolumn{6}{|l|}{ AVF MD (dB) } \\
\hline Better eye & & & 8.75 & 7.16 & $0.1-25.2$ \\
\hline Worse eye & & & 20.47 & 11.04 & $0.2-40$ \\
\hline HADS-P total score & & & 10 & 5.68 & $1.0-27$ \\
\hline HADS-A subscore & & & 6 & 3.56 & $0-16$ \\
\hline HADS-D subscore & & & 4 & 2.92 & $0-11$ \\
\hline
\end{tabular}

IOP: intraocular pressure

The mean duration of glaucoma was 5.82 years \pm 5.83 standard deviation, with a range of 0.8 to 29 years. The mean total HADS-P score was $10 \pm 5.68$, ranging from 1.0 to 27. The mean subscores of HADS-A and HADS-D among the participants were $6 \pm 3.56$ (range from 0 to 16 ) and $4 \pm 2.92$ (range from 0 to 11), respectively.

The prevalence of anxiety and depression among the participants is shown in Figures 1 and 2, respectively. HADS-A score $\geq 11$ was seen in 15\% of cases, indicating anxiety in glaucoma patients. Borderline cases of anxiety were observed in $20 \%$ (HADS-A score of $8-10$ ), and $65 \%$ were normal, with a HADS-A 
Risk factors for anxiety and depression in glaucoma patients

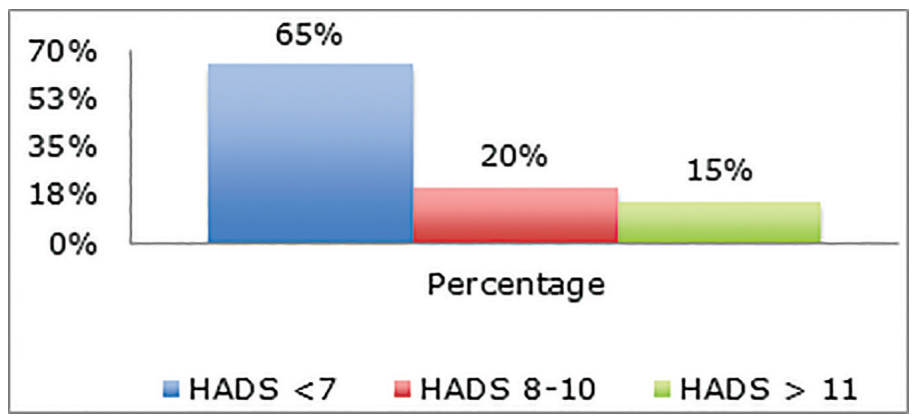

Fig. 1. HADS-P score for anxiety.

score $\leq 7$ (Fig. 1). Similarly, clinically diagnosed (HADS-D score of $\geq 11$ ) cases of depression were $1 \%$, borderline cases (HADS-D 8-10) were $12 \%$, and patients with normal HADS-D score were $87 \%$ (Fig. 2).

To show the relationship between the independent variables and anxiety (HADS-A subscore), Pearson correlation and linear regression were conducted. The results showed that there was a statistically significant correlation between HADS-A and age $(r=-0.273, p=0.0119$; Table 2$)$, logMAR BCVA of the worse eye $(r=0.191, p=0.085$; Table 2$)$, and MD of the worse eye $(r=0.247, p=0.025$; Table 2). The linear regression analysis was conducted to confirm the Pearson correlation results and revealed statistically significant relationships between: HADS-A subscore and age ( $B=-0.07, p=0.0129$; Table 3 , Fig. 3 ); logMAR BCVA of the worse eye and HADS-A subscore $(B=0.424, p=0.086$; Table 3$)$; and MD of the worse eye and HADS-A subscore $(B=0.078, p=0.025$; Table 3$)$.

Pearson correlation and linear regression were conducted to determine the relationship between the independent variables and depression (HADS-D

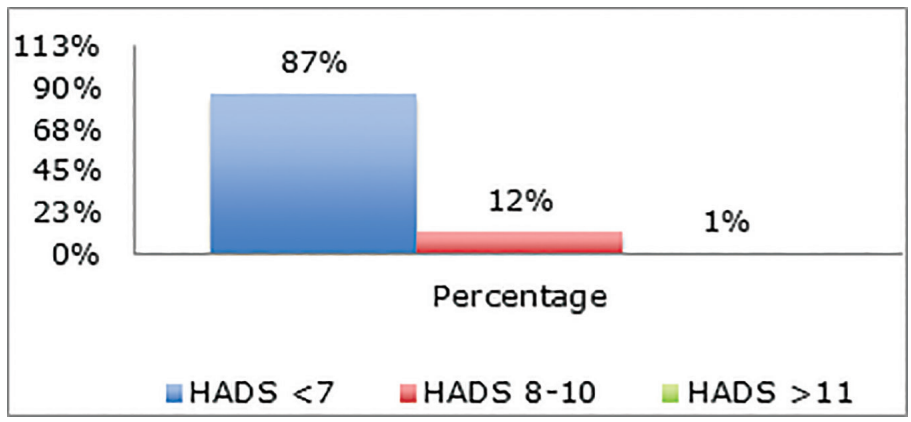

Fig. 2. HADS-P score for depression. 
Table 2. Pearson correlation for anxiety (HADS-A)

\begin{tabular}{|c|c|c|}
\hline Category & Correlation with HADS-A & p Value \\
\hline Age, years & -0.273393685 & $0.0119^{a}$ \\
\hline \multicolumn{3}{|c|}{ LogMAR BCVA } \\
\hline Better eye & -0.017163989 & 0.879 \\
\hline Worse eye & 0.191386096 & $0.085^{\mathrm{a}}$ \\
\hline \multicolumn{3}{|c|}{ AVF MD (dB) } \\
\hline Better eye & 0.114971832 & 0.297 \\
\hline Worse eye & 0.247043223 & $0.0252^{\mathrm{a}}$ \\
\hline
\end{tabular}

${ }^{a} p<0.1$ considered significant

Table 3. Linear regression analysis for anxiety (HADS-A)

\begin{tabular}{|l|l|l|l|l|l|l|}
\hline Category & DFn, DFd & F & R $^{2}$ & Constant & B & p Value \\
\hline Age, years & 1,80 & 6.463 & 0.07474 & 10.7 & -0.07011 & $0.0129^{\mathrm{a}}$ \\
\hline \multicolumn{7}{|l|}{ LogMAR BCVA } \\
\hline Better eye & 1,80 & 0.02679 & 0.0003347 & 6.47 & -0.4080 & 0.8704 \\
\hline Worse eye & 1,80 & 3.032 & 0.03652 & 5.729 & 0.4240 & $0.0855^{\mathrm{a}}$ \\
\hline AVF MD (dB) & & & & \\
\hline Better eye & 1,80 & 1.072 & 0.01322 & 5.878 & 0.05711 & 0.3037 \\
\hline Worse eye & 1,80 & 5.200 & 0.06103 & 4.747 & 0.07965 & $0.0253^{\mathrm{a}}$ \\
\hline
\end{tabular}

DFn: the degree of freedom for the numerator of the $\mathrm{F}$ ratio; DFd: denominator ${ }^{\mathrm{a}} \mathrm{p}<0.1$ considered significant

subscore). The results showed that there was a statistically significant correlation between age ( $r=-0.275, p=0.0115$; Table 4), logMAR BCVA of the worse eye $(r=0.299, p=0.006$; Table 4$)$, and MD of the worse eye $(r=0.266, p=0.016$; Table 4) and better eye $(r=0.238, p=0.032$; Table 4). The linear regression analysis revealed the following statistically significant relationships: HADS-D subscore and age ( $B=-0.06, p=0.0125$; Table 5, Fig. 4); logMAR BCVA of the worse eye and HADS-D subscore $(B=0.541, p=0.006$; Table 5$)$; $M D$ of the worse eye and HADS-D subscore $(B=0.070, p=0.016$; Table 5$)$; and MD of the better eye and HADS-D subscore $(B=0.097, p=0.032$; Table 5$)$. 


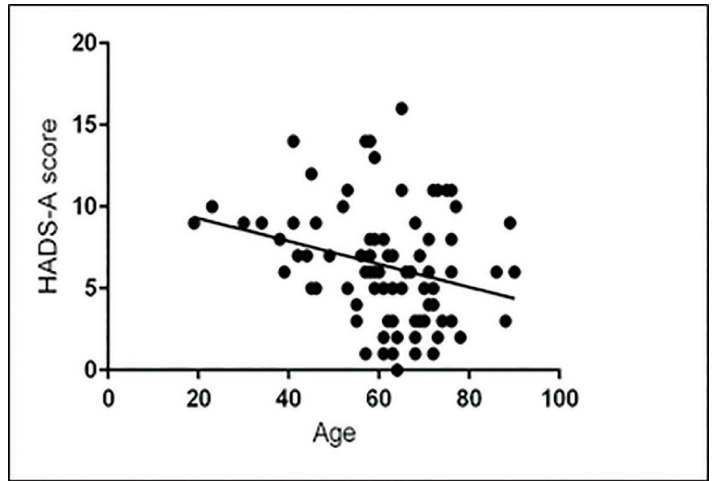

Fig. 3. Linear regression plot between age and HADS-A score.

Table 4. Pearson correlation for depression (HADS-D)

\begin{tabular}{|l|l|l|}
\hline Category & Correlation with HADS-D & p Value \\
\hline Age, years & -0.274682999 & $0.0115^{\mathrm{a}}$ \\
\hline LogMAR BCVA & 0.026691152 & 0.8124 \\
\hline Better eye & 0.298974388 & $0.006^{\mathrm{a}}$ \\
\hline Worse eye & & \\
\hline AVF MD (dB) & 0.237480083 & $0.032^{\mathrm{a}}$ \\
\hline Better eye & 0.265541095 & $0.016^{\mathrm{a}}$ \\
\hline Worse eye & &
\end{tabular}

${ }^{a} p<0.1$ considered significant

Tables 6 and 7 show the average BCVA of both the better and worse eye in logMAR to each HADS subclass; it is noted that patients with poorer BCVA in the worse eye would also correspond to a higher HADS score.

The average and range of VF MD in decibels are also presented in Tables 8 and 9 to show the corresponding VF defect and equivalent HADS score of the patients who participated in the study.

The patients were also categorized based on the type of glaucoma they had and the equivalent scores for each HADS subclass, as shown in Tables 10 and 11 . The patients were grouped into PACG, POAG, and SG. 
Table 5. Linear regression analysis for HADS-D

\begin{tabular}{|l|l|l|l|l|l|l|}
\hline Category & DFn, DFd & F & $R^{2}$ & Constant & B & p Value \\
\hline Age, years & 1,80 & 6.529 & 0.07545 & 7.546 & -0.0578 & $0.0125^{\mathrm{a}}$ \\
\hline LogMAR BCVA \\
\hline Better eye & 1,80 & 0.05845 & 0.0007301 & 3.928 & 0.4943 & 0.8096 \\
\hline Worse eye & 1,80 & 7.850 & 0.08936 & 3.156 & 0.5414 & $0.0064^{\mathrm{a}}$ \\
\hline AVF MD (dB) & \multicolumn{7}{|l|}{} \\
\hline Better eye & 1,80 & 4.781 & 0.0564 & 3.141 & 0.09675 & $0.0317^{\mathrm{a}}$ \\
\hline Worse eye & 1,80 & 6.069 & 0.07051 & 2.55 & 0.07022 & $0.0159^{\mathrm{a}}$ \\
\hline
\end{tabular}

$D F n$ : the degree of freedom for the numerator of the $\mathrm{F}$ ratio; DFd: denominator ${ }^{\mathrm{a}} \mathrm{p}<0.1$ considered significant

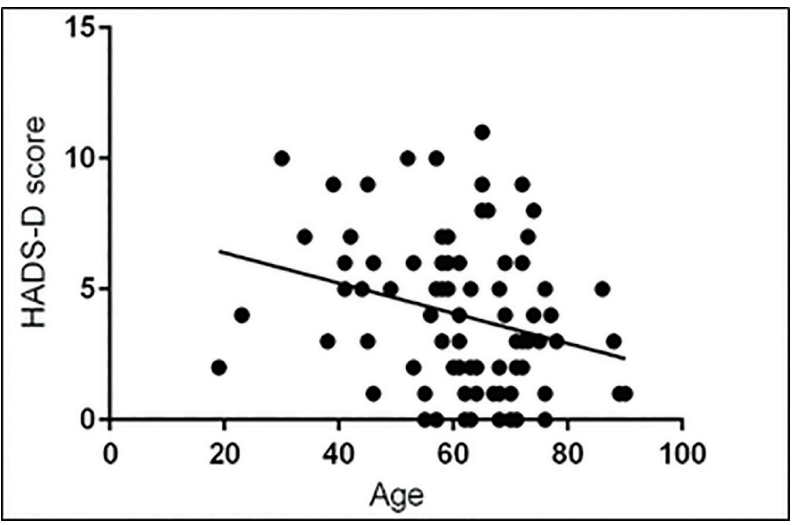

Fig. 4. Linear regression plot between age and HADS-D score.

Table 6. Mean and range of BCVA for each HADS-A category

\begin{tabular}{|l|l|l|l|l|}
\hline HADS-A & $\begin{array}{l}\text { Mean BCVA } \\
\text { of the better eye } \\
\text { (logMAR value) }\end{array}$ & $\begin{array}{l}\text { Range of BCVA } \\
\text { of the better eye } \\
\text { (logMAR value) }\end{array}$ & $\begin{array}{l}\text { Mean BCVA of } \\
\text { the worse eye } \\
\text { (logMAR value) }\end{array}$ & $\begin{array}{l}\text { Range of BCVA } \\
\text { of the worse eye } \\
\text { (logMAR value) }\end{array}$ \\
\hline HADS $\leq 7$ & 0.13 & $0-0.88$ & 1.34 & $0-4.0$ \\
\hline HADS 8-10 & 0.07 & $0-0.48$ & 1.97 & $0-4.0$ \\
\hline HADS $\geq 11$ & 0.15 & $0-0.40$ & 1.83 & $0.18-4.0$ \\
\hline
\end{tabular}


Risk factors for anxiety and depression in glaucoma patients

Table 7. Mean and range of BCVA for each HADS-D category

\begin{tabular}{|l|l|l|l|l|}
\hline HADS-D & $\begin{array}{l}\text { Mean BCVA of } \\
\text { the better eye } \\
\text { (logMAR value) }\end{array}$ & $\begin{array}{l}\text { Range of BCVA } \\
\text { of the better eye } \\
\text { (logMAR value) }\end{array}$ & $\begin{array}{l}\text { Mean BCVA of } \\
\text { the worse eye } \\
\text { (logMAR value) }\end{array}$ & $\begin{array}{l}\text { Range of BCVA } \\
\text { of the worse eye } \\
\text { (logMAR value) }\end{array}$ \\
\hline HADS $\leq 7$ & 0.11 & $0-0.88$ & 1.44 & $0-4.0$ \\
\hline HADS 8-10 & 0.14 & $0-0.30$ & 2.15 & $0-4.0$ \\
\hline HADS $\geq 11$ & 0.40 & 0.40 & 2.00 & 2.0 \\
\hline
\end{tabular}

Table 8. Mean and range of AVF (MD) for each HADS-A category

\begin{tabular}{|l|l|l|l|l|}
\hline HADS-A & $\begin{array}{l}\text { Mean AVF } \\
\text { of the better } \\
\text { eye (MD in dB) }\end{array}$ & $\begin{array}{l}\text { Range of AVF } \\
\text { of the better } \\
\text { eye (MD in dB) }\end{array}$ & $\begin{array}{l}\text { Mean AVF } \\
\text { of the worse } \\
\text { eye (MD in dB) }\end{array}$ & $\begin{array}{l}\text { Range of AVF } \\
\text { of the worse } \\
\text { eye (MD in dB) }\end{array}$ \\
\hline HADS $\leq 7$ & 8.05 & $0.1-25.2$ & 18.77 & $0.2-40$ \\
\hline HADS 8-10 & 10.71 & $0.4-23.1$ & 23.28 & $7.1-40$ \\
\hline HADS $\geq 11$ & 9.32 & $0.2-22.41$ & 24.4 & $2.92-40$ \\
\hline
\end{tabular}

Table 9. Mean and range of AVF (MD) for each HADS-D category

\begin{tabular}{|l|l|l|l|l|}
\hline HADS-D & $\begin{array}{l}\text { Mean AVF } \\
\text { of the better } \\
\text { eye (MD in dB) }\end{array}$ & $\begin{array}{l}\text { Range of AVF } \\
\text { of the better eye } \\
\text { (MD in dB) }\end{array}$ & $\begin{array}{l}\text { Mean AVF } \\
\text { of the worse eye } \\
\text { (MD in dB) }\end{array}$ & $\begin{array}{l}\text { Range of AVF } \\
\text { of the worse } \\
\text { eye (MD in dB) }\end{array}$ \\
\hline HADS $\leq 7$ & 8.14 & $0.1-25.2$ & 19.91 & $1.4-40$ \\
\hline HADS 8-10 & 12.44 & $0-25.2$ & 23.50 & $0.2-40$ \\
\hline HADS $\geq 11$ & 15.5 & 15.5 & 30 & 30 \\
\hline
\end{tabular}

Table 10. Percentage of patients in each HADS subclass for each glaucoma category.

\begin{tabular}{|l|l|l|l|}
\hline HADS-A & PACG $(\mathbf{n}=\mathbf{4 1})(\%)$ & POAG $(\mathbf{n}=\mathbf{2 6})(\%)$ & SG $(\mathbf{n}=\mathbf{1 5})(\%)$ \\
\hline HADS $\leq 7$ & 66 & 58 & 80 \\
\hline HADS 8-10 & 10 & 35 & 20 \\
\hline HADS $\geq 11$ & 24 & 8 & 0 \\
\hline
\end{tabular}


Table 11. Percentage of patients in each HADS subclass for each glaucoma category.

\begin{tabular}{|l|l|l|l|}
\hline HADS-D & PACG $(\mathbf{n}=\mathbf{4 1})(\%)$ & POAG $(\mathbf{n}=\mathbf{2 6})(\%)$ & SG $(\mathbf{n}=\mathbf{1 5}) \mathbf{( \% )}$ \\
\hline HADS $\leq 7$ & 85 & 85 & 87 \\
\hline HADS 8-10 & 12 & 15 & 7 \\
\hline HADS $\geq 11$ & 2 & 0 & 0 \\
\hline
\end{tabular}

\section{Discussion}

The chronic nature of glaucoma and associated long-term treatment, risk of blindness, cost of medicines, and surgical procedures may all be factors in the development of anxiety and depression. The prevalence of clinical anxiety (15\%) and borderline anxiety (20\%) is higher than that of clinical depression (1\%) and borderline depression (12\%), perhaps due to the stress of frequent clinic visits, economic burden of treatment, and the absence of a guaranteed cure. Patients with glaucoma might be anxious about the risk of blindness and the consequent inability to earn a living or perform normal activities of daily life. The higher prevalence of anxiety over depression is reflected in other studies. In a study by Fasih et al., ${ }^{18}$ it was noted that anxiety (33\%) is more prevalent than depression (22\%) among patients diagnosed with POAG. Similarly, a study by Mabuchi showed that patients with glaucoma are more likely to have anxiety (13\%) than depression $(10 \%){ }^{8}$

The tendency toward psychological disturbances among glaucoma patients could be due to worrying and feelings of panic as a result of the poor prognosis associated with the disease. The initial anxiety may arise from coming to terms with the condition and their hopes to find a cure that will avoid blindness.

Risk factors of glaucoma patients that make anxiety more likely include age, logMAR BCVA of the worse eye, and MD (AVF) of the worse eye. There is a negative correlation between age and the HADS-A subscore, which showed that younger patients with the condition tend to be more anxious. This is similar to the study of Mabuchi, and also Zhou, which revealed that younger patients were more likely to be anxious once they had been diagnosed with glaucoma. ${ }^{8,9}$ Younger patients also showed anxious behaviors when diagnosed with other chronic diseases, such as cancer and cardiovascular disease. ${ }^{12,19}$ As glaucoma can potentially result in bilateral blindness, younger glaucoma patients may have been more anxious about maintaining their visual function in light of their longer remaining life span. Patients with poor visual acuity and severe generalized depression, as depicted in the MD, showed a statistically significant positive correlation with the HADS-A subscore. Having poor visual acuity causes the patient to be anxious, probably due to the fear of losing their vision and their reduced future productivity. 
However, there were no significant relationships between anxiety and the type of glaucoma, duration of glaucoma, number of eye drops, or gender in this study.

Although only $1 \%$ of the participants had clinical depression and $12 \%$ had borderline depression based on the HADS-D subscore, it was still noted that younger age, logMAR BCVA of the worse eye, and MD (AVF) in both the worse and better eyes had significant correlation. This differs from the study of Mabuchi, which showed that older patients were more prone to depression. ${ }^{8}$ The fact that only a small proportion of the population is thought to suffer from depression probably accounts for the disparity between this study and Mabuchi's in the correlation between age and HADS-D subscore. Different races and ethnicities may have different coping mechanisms and psychological reactions toward the disease. In a Filipino study by de Guzman, ${ }^{20}$ the validation of the translated HADS questionnaire showed that both anxiety and depression were higher among patients in the younger age group (18-35 years), which is similar to the negative correlation shown in this study. This psychopathological finding is probably due to the combination of stresses caused by coping with a chronic, potentially blinding condition during a person's most productive years. Similar to the study of Mabuchi et al., ${ }^{8}$ depression had a positive correlation with poor visual acuity and increased severity in the MD of the AVFs. This can probably be attributed to worsening visual prognosis, which may have contributed to depression in the patient. In this study, the likelihood of patients suffering from anxiety or depression was not impacted by whether they had POAG, PACG, or SG. Factors such as marital status, educational status, or whether subjects lived with others or alone made no statistical difference. This may be because the majority of participants are likely to be in a low-income bracket, as this study was conducted in a single-center, government tertiary hospital.

The limitations of this study are as follows: the majority of participants had moderate or advanced generalized VF defects, which probably resulted in a statistically significant positive correlation for the HADS score. Most of the patients seen in this institution were referrals from other hospitals, meaning the disease could either be advanced or already end-stage, which could have affected the HADS scores. The majority of patients also belonged to a lower socioeconomic background and had a lower educational status, which could have affected their HADS scores. Although the HADS is simple and lends itself to studies such as this, a questionnaire is not comparable with a formal psychiatric diagnosis of depression or anxiety. A follow-up study can be conducted where patients with high HADS scores will be formally referred to a specialist for further evaluation. A multicenter study is recommended to broaden the mix of patients' socioeconomic status and severity of glaucoma. A larger sample size is also recommended in order to strengthen the statistical relationships between the variables presented. 


\section{Conclusion}

Our study shows that the prevalence of anxiety is higher than that of depression in patients with glaucoma. It is therefore suggested that in addition to evaluation and treatment of glaucoma patients, ophthalmologists should be aware of the possible psychological disturbances this condition brings to a patient, and prompt referral for further evaluation of this conditions should be conducted.

It can also be concluded that young age was found to be a risk factor for both anxiety and depression. The patient's visual acuity in the worse eye and VF severity are also risk factors for both anxiety and depression. It is therefore essential for physicians to be aware of the risk factors for anxiety and depression in patients with glaucoma and to provide glaucoma patients with appropriate psychological care, in addition to ophthalmological care, to reduce or eliminate the likelihood of developing anxiety and depression.

\section{Acknowledgment}

The authors have no financial, proprietary, or commercial interest in any of the materials used in this study.

\section{References}

1. Janz NK, Wren PA, Guire KE, et al. Fear of blindness in the Collaborative Initial Glaucoma Treatment Study: patterns and correlates over time. Ophthalmology. 2007;114:2213-2220.

2. Jampel HD, Frick KD, Janz NK, et al. Depression and mood indicators in newly diagnosed glaucoma patients. Am J Ophthalmol. 2007;144:238-244.

3. Mabuchi F, Yoshimura K, Kashiwagi K, et al. High prevalence of anxiety and depression in patients with primary open-angle glaucoma. J Glaucoma. 2008;17:552-557.

4. Wang SY, Singh K, Lin SC. Prevalence and predictors of depression among participants with glaucoma in a nationally representative population sample. Am J Ophthalmol. 2012;154:436. e2-444.e2.

5. Chan EW, Chiang, PP, Liao J, et al. Glaucoma and associated visual acuity and field loss significantly affect glaucoma-specific psychosocial functioning. Ophthalmology. 2014;122:494-501; Manuscript no. 2014-89.

6. American Psychiatric Association. Diagnostic and statistical manual of mental disorders: DSM-5. 5th ed. Washington, DC: American Psychiatric Association; 2013:222.

7. Tastan S, lyigun E, Bayer A, et al. Anxiety, depression, and quality of life in Turkish patients with glaucoma. Psychol Rep. 2010;106:343-357.

8. Mabuchi F, Yoshimura K, Kashiwagi K, et al. Risk factors for anxiety and depression in patients with glaucoma. Br J Ophthalmol. 2012;96:821-825.

9. Zhou C, Qian S, Wu P, et al. Anxiety and depression in Chinese patients with glaucoma: sociodemographic, clinical, and self-reported correlates. J Psychosom Res. 2013;75:75-82.

10. Kong XM, Zhu WQ, Hong JX, et al. Is glaucoma comprehension associated with psychological disturbance and vision-related quality of life for patients with glaucoma? A cross-sectional study. BMJ Open. 2014;4:e004632. doi:10.1136/bmjopen-2013-004632

11. Zigmond AS, Snaith RP. The hospital anxiety and depression scale. Acta Psychiatr Scand. 1983;67:361-370. 
12. Kugaya A, Akechi T, Okuyama T, et al. Screening for psychological distress in Japanese cancer patients. Jpn J Clin Oncol. 1998;28:333e8.

13. Astejada MN, Jamora RD, Ledesma LK, Bacsal FE. Screening for anxiety and depression among adult Filipino epileptics using the Hospital Anxiety and Depression Scale. Neurol Asia. 2004;9(Suppl 1):137.

14. Tan SK, Benedicto J, Santiaguel J, et al. Prevalence of anxiety and depression among Filipino patients with chronic obstructive pulmonary disease: a multi-center study. 2012. Unpublished.

15. Tan SK, Benedicto J, Santiaguel J, et al. Determinants of anxiety and depression among Filipino patients with chronic obstructive pulmonary disease: a multi-center study. Eur Respir J. 2013;42(Suppl. 57):P4183.

16. Cubillan LDP, Santos EO. Third national survey on blindness. Philipp J Ophthalmol. 2005;30:100-114.

17. Lloyd GG. Psychological precursors of physical illness: textbook of general hospital psychiatry. Churchill Livingstone; 1991:15.

18. Fasih U, Hamirani MM, Asad R, Riaz U. Assessment of anxiety and depression in primary open angle glaucoma patients. Pakistan J Ophthalmol. 2010;26(3):143-147.

19. Wang W, Chair SY, Thompson DR, et al. A psychometric evaluation of the Chinese version of the Hospital Anxiety and Depression Scale in patients with coronary heart disease. J Clin Nurs. 2009;18:1908-1915.

20. de Guzman MLRE. A validation of the hospital anxiety and depression scale (HADS) in the medically-ill. Acta Medica Philippina. 2013;47(3):53-62.

21. WHOQOL group. Study protocol for the World Health Organization project to develop a Quality of Life assessment instrument (WHOQOL). Qual Life Res. 1993;2:153-159.

22. Spaeth G, Walt J, Keener J. Evaluation of quality of life for patients with glaucoma. Am J Ophthalmol. 2006;141:S3-S14. 


\section{Appendix A. HADS-P questionnaire}

\section{Hospital Anxiety and Depression Scale-Pilipino Translation (HADS-P)}

Direksyon: Maari pong pakisagutan ang mga sumusunod na tanong sa pamamagitan ng paglagay ng sa kahon na mahahayeg $n g$ inyong palagay. Wala pong tama o maing kasagutan sa bajwat tanong.

\begin{tabular}{|c|c|}
\hline $\begin{array}{l}\text { 1. Naliligalig at punong-puno na ako. } \\
\text { Mas madalas kaysa hindi } \\
\text { Madalas } \\
\text { Paminsan-minsan } \\
\text { Hinding-hindi }\end{array}$ & $\begin{array}{l}\text { 2. Pakiramdam ko parang pinapabagal ako. } \\
\text { Halos lagi-lagi } \\
\text { Napakadalas } \\
\text { Minsan } \\
\text { Hinding-hindi }\end{array}$ \\
\hline $\begin{array}{l}\text { 3. Ikinasasaya ko pa rin ang mga bagay na dati ko } \\
\text { nang ikinasassya. } \\
\text { Katulad din ng dati } \\
\text { Hindi na kasingdalas } \\
\text { Konti lang } \\
\text { Halos hindi na } \\
\end{array}$ & $\begin{array}{l}\text { 4. Para akong natatakot na may nararamdamang } \\
\text { sobrang nerbiyos. } \\
\text { Hinding-hindi } \\
\text { Paminsan-minsan } \\
\text { Medyo madalas } \\
\text { Madalas na madalas }\end{array}$ \\
\hline $\begin{array}{l}\text { 5. Para akong nakakaramdam na may mangyayaring } \\
\text { masama. } \\
\text { Lagi-lagi at medyo malala } \\
\text { Palagi pero di-gaanong malala } \\
\text { Konti pero di ako nag-aalala } \\
\text { Hinding-hindi }\end{array}$ & $\begin{array}{l}\text { 6. Nawalan na ako ng interes sa aking hitsura. } \\
\text { Talaga } \\
\text { Hindi ako nangangalaga ng dapat } \\
\text { Pwedeng hindi ako magalaga ng } \\
\text { nararapat } \\
\text { Pinangangalagaan ko pa rin ito tulad } \\
\text { ng dati }\end{array}$ \\
\hline $\begin{array}{l}\text { 7. Kaya ko pang tumawa at mapansin ang } \\
\text { nakakatuwang bahagi sa mga bagay-bagay. } \\
\text { Lagi-lagi tulad ng dati } \\
\text { Mas madalang na ng kaunti jaysa dati } \\
\text { Hindi na katulad ng dati } \\
\text { Hinding-hindi }\end{array}$ & $\begin{array}{l}\text { 8. Hindi ako mapakali na parang gusto kong may } \\
\text { pinakakaabalahan. } \\
\text { Talagang madalas } \\
\text { Mcdyo madalas } \\
\text { Di naman gaano } \\
\text { Hinding-hindi }\end{array}$ \\
\hline $\begin{array}{l}\text { 9. Pag-aalala ang nasa isip ko. } \\
\text { Madalas na madalas } \\
\text { Madalas } \\
\text { Di gaanong madalas } \\
\text { Konting-konti } \\
\end{array}$ & $\begin{array}{l}\text { 10. Masaya akong umassa sa bagay-bagay } \\
\text { Kasingdalas ng nakagawian ko } \\
\text { Di-kasingdalas ng nakkagawian ko } \\
\text { Mas madalang kaysa nakagawian ko } \\
\text { Halos hindi na }\end{array}$ \\
\hline $\begin{array}{l}\text { 11. Masaya and aking pakiramdam. } \\
\text { Hindi kailanman } \\
\text { Madalang } \\
\text { Paminsan-minsan } \\
\text { Kadalasan } \\
\end{array}$ & $\begin{array}{l}\text { 12. Bigla akong nakakaramdam ng pagkasindak. } \\
\text { Madalas na madalas } \\
\text { Mcdyo madalas } \\
\text { Di gasnong madalas } \\
\text { Hinding-hindi }\end{array}$ \\
\hline $\begin{array}{l}\text { 13. Kaya kong umupo ng kumportable at mag-relax. } \\
\text { Palagi } \\
\text { Madalas } \\
\text { Madalang } \\
\text { Hinding-hindi }\end{array}$ & $\begin{array}{l}\text { 14. Kaya akong masliw sa isang magandang libro o } \\
\text { programa sa radio o TV. } \\
\text { Madalas } \\
\text { Paminsan-minsan } \\
\text { Madalang } \\
\text { Hinding-hindi }\end{array}$ \\
\hline
\end{tabular}




\section{Appendix B. HADS questionnaire (English)}

\section{Hospital Anxiety and Depression Scale (HADS)}

Tick the box beside the reply that is closest to how you have been feeling in the past week.

Don't take too long over you replies: your immediate is best.

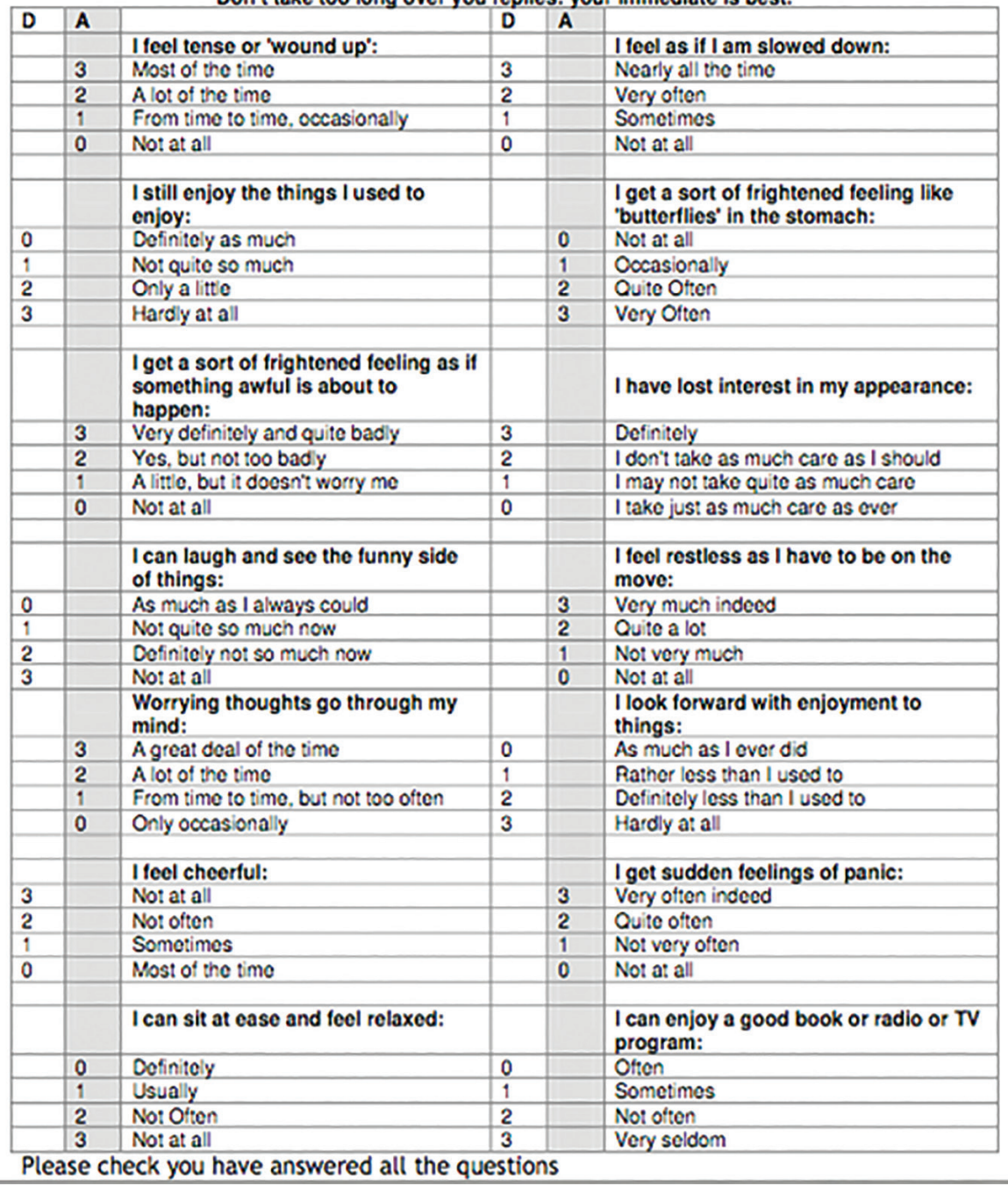

